\title{
Translation of Three Mouse Hepatitis Virus Strain A59 Subgenomic RNAs in Xenopus laevis Oocytes
}

\author{
PETER J. M. ROTTIER,* WILLY J. M. SPAAN, MARIAN C. HORZINEK, AND BERNARD A. M. VAN \\ DER ZEIJST $†$
}

Institute of Virology, Veterinary Faculty, State University, 3508 TD Utrecht, The Netherlands

Received 8 October 1980/Accepted 17 December 1980

\begin{abstract}
We have purified the seven virus-specific RNAs which were previously shown to be induced in Sac(-) cells upon infection with mouse hepatitis virus strain A59 (W. J. M. Spaan, P. J. M. Rottier, M. C. Horzinek, and B. A. M. van der Zeijst, Virology 108:424-434, 1981). The individual RNAs, prepared by agarose gel electrophoresis of the polyadenylated RNA fraction from infected cells, were obtained pure, except for the preparations of RNAs 4, 5, and 6, which contained some contamination of RNA 7. The RNAs were microinjected into Xenopus laevis oocytes, and after incubation of these cells in the presence of $\left[{ }^{35} \mathrm{~S}\right] \mathrm{methio-}$ nine, the proteins synthesized were analyzed by polyacrylamide gel electrophoresis. Whereas no translation products of RNAs $1,2,4$, and 5 were detected, the synthesis of virus-specific polypeptides coded by RNAs 3, 6, and 7 was observed. RNA $7\left(0.6 \times 10^{6}\right.$ daltons) directed the synthesis of a 54,000-molecular-weight polypeptide which comigrated with viral nucleocapsid protein and which was immunoprecipitated by antiserum from mice that had been infected with the virus. RNA $6\left(0.9 \times 10^{6}\right.$ daltons $)$ directed the synthesis of three polypeptides with molecular weights of $24,000,25,500$, and 26,500 , which migrated with the same electrophoretic mobilities as three low-molecular-weight virion polypeptides. After injection of RNA $3\left(3.0 \times 10^{6}\right.$ daltons), a polypeptide with a molecular weight of about 150,000 was immunoprecipitated. This polypeptide had no counterpart in the virion, but comigrated with a virus-specific glycoprotein present in infected cells which is immunoprecipitated by a rabbit antiserum against the mouse hepatitis virus strain A59 structural proteins. This antiserum could also immunoprecipitate the translation products of RNAs 3,6, and 7. These results indicate that RNAs 3, 6, and 7 encode viral structural proteins. The significance of the data with respect to the strategy of coronavirus replication is discussed.
\end{abstract}

Mouse hepatitis virus strain A59 (MHV-A59) is a member of the Coronaviridae (14). These are lipid-enveloped viruses with a singlestranded infectious RNA genome of about $6 \times$ $10^{6}$ molecular weight (7). Published data on coronavirus structural proteins are inconsistent, but MHV-A59 has been reported to contain at least three structural polypeptides (12): one nucleocapsid protein of about 50,000 daltons, which is phosphorylated (11), and two envelope glycoproteins with molecular weights of about 23,000 and 90,000. A fourth polypeptide present in the virion envelope, a glycoprotein of about 180,000 daltons, presumably is a dimer of the 90,000 dalton species (13).

Little information is available about the replication of coronaviruses. Some four to nine virus-specific proteins have been detected in cells

† Person to receive reprint requests. upon infection with MHV strains JHM and MHV3 and MHV-A59 (1, 3, 9). One of these proteins corresponds to the nucleocapsid protein, and another corresponds to the smaller envelope glycoprotein (9). A larger, 150,000-dalton glycoprotein is thought to be related to the high-molecular-weight envelope glycoprotein (9), although it was shown to be distinctly smaller than its virion counterpart in the case of JHM virus. The nature of the other virus-specific proteins remains unclear.

Recently, we found that infection of Sac(-) cells with MHV-A59 induced the synthesis of six virus-specific subgenomic RNAs (9a). In addition to the $5.6 \times 10^{6}$-dalton genome-sized RNA 1, RNAs with molecular weights of $4.0 \times 10^{6}, 3.0$ $\times 10^{6}, 1.4 \times 10^{6}, 1.2 \times 10^{6}, 0.9 \times 10^{6}$, and $0.6 \times$ $10^{6}$ (designated as RNAs 2 to 7 , respectively) were detected in infected cells in which host cell RNA synthesis had been shut off by actinomycin 
D. Since all RNA species contained polyadenylic acid [poly(A)] and were present in polysomes, we concluded that they are probably functional messengers. Since the sum of the molecular weights of the six MHV-A59 subgenomic RNAs is almost twice that of the genome, we postulated that nucleotide sequence homologies exist between the subgenomic MHV-A59 RNAs. Comparable observations have also been reported recently for an avian coronavirus by Stern and Kennedy (10). These authors demonstrated that in chicken cells infected with infectious bronchitis virus, in addition to genome-sized RNA, five polyadenylated [poly $\left.(A)^{+}\right]$single-stranded virus-specific RNAs were synthesized, whose sizes roughly corresponded to those of MHV-A59 RNAs 3 to 7. However, no RNA species with the approximate size of RNA 2 was detected. By comparison of $R$ Nase $T_{1}$ fingerprints of infectious bronchitis virus RNAs, it was shown that the sequences of the four smaller subgenomic RNAs are indeed present in the genome and that the sequence of each RNA is contained within all larger ones (10).

As a working hypothesis for the further study of the infection process caused by MHV-A59, we proposed a speculative model in which two points were central (9a). First, the nucleotide sequence of each subgenomic RNA is identical to the $3^{\prime}$ part of the genome; i.e., each RNA contains a $5^{\prime}$-terminal sequence extension with respect to the next smaller one. Second, all RNAs are messengers, the expression of which occurs by translation of only that $5^{\prime}$-terminal part of the RNA not present in the next smaller RNA; internal initiation of translation does not occur. As a first approach in testing this model, we have purified the virus-specific RNAs induced in Sac(-) cells upon infection with MHV A59 and presented them to a suitable translation system. The Xenopus laevis oocyte system was selected since it is known to translate large-sized mRNA's with high fidelity and without premature termination, as is often the case in cell-free systems (8), and to carry out the post-translational modifications of the protein products, if necessary (F. A. M. Asselbergs, Ph.D. thesis, University of Nijmegen, Nijmegen, The Netherlands, 1979). The results presented in this paper demonstrate that at least three of the RNAs function as messengers, yielding proteins that can be immunoprecipitated specifically with antisera directed against the viral proteins. The molecular weights of these translation products agree with the theoretical values expected on the basis of our working model.

\section{MATERIALS AND METHODS}

Cells and virus. MHV-A59 was grown in Sac(-) cells. Monolayer cultures at a density of about $2 \times 10^{5}$ Sac(-) cells per $\mathrm{cm}^{2}$ were inoculated with the virus at a multiplicity of infection of 10 PFU per cell in Dulbecco-modified Eagle medium (DMEM)-3\% fetal calf serum $(0.3 \mathrm{ml}$ per $35-\mathrm{mm}$ tissue culture dish; $5 \mathrm{ml}$ per 75- $\mathrm{cm}^{2}$ tissue culture flask; $10 \mathrm{ml}$ per $490-\mathrm{cm}^{2}$ Corning roller bottle). After a 1-h adsorption period at $37^{\circ} \mathrm{C}$, cells were incubated further with DMEM-10\% fetal calf serum $(1,10$, and $50 \mathrm{ml}$, respectively). MHV-A59 was purified from culture medium as described previously (9a).

Isolation of virus-specific intracellular RNAs. Cytoplasmic poly(A)-containing RNA was isolated from MHV-A59-infected Sac(-) cells grown in five Corning roller bottles essentially as described previously $(9 a)$. Briefly, the cells to which were added actinomycin D (1 $\mu \mathrm{g} / \mathrm{ml}$; Serva, Heidelberg, Germany) and $\left[5{ }^{3} \mathrm{H}\right]$ uridine $(1 \mu \mathrm{Ci} / \mathrm{ml}, 28 \mathrm{Ci} / \mathrm{mmol}$; The Radiochemical Centre, Amersham, England) at 3.5 and 4.5 h postinfection (p.i.), respectively, were lysed at $9 \mathrm{~h}$ p.i. with $20 \mathrm{ml}$ of $0.5 \%$ Triton X-100-0.5\% 1,5-naphthalenedisulfonate $\cdot \mathrm{Na}_{2}$ in TES (20 mM Tris [pH 7.4], 1 mM EDTA, $100 \mathrm{mM} \mathrm{NaCl}$ ). After centrifugation of the lysate for $5 \mathrm{~min}$ at $2,000 \times \mathrm{g}$, an equal volume of TES containing $2 \%$ sodium dodecyl sulfate (SDS) and $7 \mathrm{M}$ urea was added to the supernatant, and RNA was isolated by phenol extraction and ethanol precipitation. The dried RNA was dissolved in TES containing 1\% SDS and 3.5 $\mathrm{M}$ urea and reextracted with phenol. The final RNA precipitate was dissolved in high-salt binding buffer (10 mM Tris [pH 7.5], 0.05\% SDS, 0.5 $\mathrm{M} \mathrm{NaCl}$ ) and subjected to oligodeoxythymidylic acid cellulose chromatography. To remove residual nonpoly(A)-containing RNA species, the material eluted with $10 \mathrm{mM}$ Tris-hydrochloride (pH 7.5) was rechromatographed and poly(A)-containing RNA was recovered by ethanol precipitation.

${ }^{32}$-labeling of virus-specific intracellular RNAs. Monolayer cultures $\left(10^{6}\right.$ cells per $35-\mathrm{mm}$ tissue cul-ure dish) were infected as described above, except after adsorption the cells were washed once with salt solution A (137 mM NaCl, $4 \mathrm{mM} \mathrm{KCl}, 1.6 \mathrm{mM} \mathrm{CaCl}_{2}$

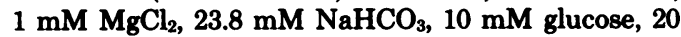
mg of phenol red [pH 7.2] per liter). The cells were incubated with $1 \mathrm{ml}$ of phosphate-free DMEM, buffered with $20 \mathrm{mM}$ HEPES ( $N$-2-hydroxyethylpiperazine- $N^{\prime}$-2-ethanesulfonic acid)- $\mathrm{KOH}$ at $\mathrm{pH} 7.2$, and supplemented with $10 \%$ dialyzed fetal calf serum. Actinomycin D (1 $\mu \mathrm{g} / \mathrm{ml})$ was added at $4 \mathrm{~h}$ p.i. After $1 \mathrm{~h}, 150 \mu \mathrm{Ci}$ of carrier-free ${ }^{32} \mathrm{P}_{\mathrm{i}}$ (The Radiochemical Centre) per ml was added. The cells were lysed at $8 \mathrm{~h}$ p.i., and RNA was extracted as described previously (9a).

Analytical agarose gel electrophoresis. RNA samples were denatured with glyoxal and dimethyl sulfoxide and analyzed by electrophoresis in a $1 \%$ agarose-6 $M$ urea horizontal slab gel as described previously (9a).

Preparative agarose gel electrophoresis. About $300 \mu \mathrm{g}$ of the poly(A)-containing RNA fraction extracted from MHV-A59-infected Sac(-) cells was dissolved in $250 \mu \mathrm{l}$ of $10 \mathrm{mM}$ sodium phosphate $(\mathrm{pH} 7.0)$ containing $1 \mathrm{mM}$ EDTA, $0.25 \%$ SDS, and $10 \mu \mathrm{g}$ of bromophenol blue per $\mathrm{ml}$ and mixed with 140,000 Cerenkov counts per minute of ${ }^{32} \mathrm{P}$-labeled poly $(\mathrm{A})^{+}$ MHV-A59 intracellular RNA. The solution was heated 
for $5 \mathrm{~min}$ at $56^{\circ} \mathrm{C}$, rapidly cooled on ice, and placed in a slot $(40$ by $2 \mathrm{~mm}$ ) of a horizontal $1 \%$ agarose-6 $\mathrm{M}$ urea slab gel ( 19 by 19 by $0.2 \mathrm{~cm}$ ).

The gel was run under the same conditions as those used for analytical electrophoresis. RNA bands were located by autoradiography of the wet gel, excised, and kept at $-70^{\circ} \mathrm{C}$.

Elution of RNA from gel slices. The gel slices were taken up in $0.7 \mathrm{ml}$ of electrophoresis buffer (40 $\mathrm{mM}$ Tris, $20 \mathrm{mM}$ sodium acetate, $33 \mathrm{mM}$ acetic acid, $2 \mathrm{mM}$ EDTA [pH 7.4]) and melted by incubation at $65^{\circ} \mathrm{C}$ for $5 \mathrm{~min}$. An equal volume of phenol saturated with TES was vigorously mixed with the melted gel. After separation of the phases by centrifugation at room temperature, the agarose was present as a solid layer between the aqueous and phenol phases. Twothirds of the aqueous layer was removed. To the remaining part $0.5 \mathrm{ml}$ of electrophoresis buffer was added, and after mixing and centrifugation again twothirds of the aqueous phase was pipetted off. The RNA in the combined aqueous phases was ethanol precipitated and dried. Each RNA preparation was dissolved in $10 \mu \mathrm{l}$ of water and stored at $-70^{\circ} \mathrm{C}$.

Translation of RNAs in $X$. laevis oocytes. RNA samples were diluted with an equal volume of doubleconcentrated Gurdon injection solution (5); batches of 16 oocytes were microinjected, each cell with $50 \mathrm{nl}$, as described by Asselbergs et al. (2). Oocytes were labeled in modified Barth medium (4) with $0.5 \mathrm{mCi}$ of $\mathrm{L}$ $\left[{ }^{35} \mathrm{~S}\right]$ methionine $(890 \mathrm{Ci} / \mathrm{mmol}$; The Radiochemical Centre) per $\mathrm{ml}$ for $22 \mathrm{~h}$ at $19^{\circ} \mathrm{C}$. The cells were washed with unlabeled medium and stored frozen at $-70^{\circ} \mathrm{C}$. They were homogenized by using a minipotter with lysis buffer $(0.5 \%$ Triton X-100-0.5\% 1,5-naphthalenedisulfonate $\cdot \mathrm{Na}_{2}-500$ kallikrein units of Trasylol [Bayer, Leverkusen, Germany] per ml-2 mM phenylmethylsulfonyl fluoride in TES; $15 \mu \mathrm{l}$ per oocyte) and centrifuged for $2 \mathrm{~min}$ at $10,000 \times \mathrm{g}$. Pellets were reextracted with the same volume of lysis buffer and centrifuged again. The combined supernatants were overlaid with $3 \mathrm{ml}$ of paraffin oil and centrifuged for $15 \mathrm{~min}$ at $60,000 \times g$ and $5^{\circ} \mathrm{C}$. The aqueous phases were removed for analysis.

Radioactive labeling of viral structural proteins. Monolayer cultures of $\operatorname{Sac}(-)$ cells $\left(2 \times 10^{7}\right.$ cells per $75-\mathrm{cm}^{2}$ tissue culture flask) were infected with MHV-A59 and incubated as described above. Virus was labeled with ${ }^{3} \mathrm{H}$-amino acids (a mixture of lysine, tyrosine, leucine, phenylalanine, and proline; 65 to 150 $\mathrm{Ci} / \mathrm{mmol}$; The Radiochemical Centre) by incubating the cells from 5 to $10 \mathrm{~h} \mathrm{p.i.} \mathrm{in} 6 \mathrm{ml}$ of minimal essential medium containing $1 / 10$ the normal concentration of lysine, tyrosine, leucine, and phenylalanine, $2 \%$ fetal calf serum, and $50 \mu \mathrm{Ci}$ of the ${ }^{3} \mathrm{H}$-labeled amino acid mixture per $\mathrm{ml}$.

To label virus with ${ }^{32} \mathbf{P}$, cells were washed twice with salt solution $A$ at $3.5 \mathrm{~h}$ p.i. and further incubated for $7 \mathrm{~h}$ in phosphate-free DMEM supplemented with $2 \%$ dialyzed fetal calf serum and buffered with $20 \mathrm{mM}$

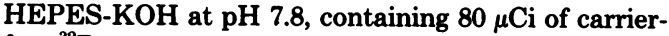
free ${ }^{32} \mathbf{P}_{\mathrm{i}}$

Radioactive labeling of intracellular virusspecific proteins. Sac $(-)$ cells grown in a $35-\mathrm{mm}$ plastic dish were infected with MHV-A59 and incu- bated under standard conditions. At $5 \mathrm{~h}$ p.i., the cells were washed twice with phosphate-buffered saline and incubated further in the presence of ${ }^{3} \mathrm{H}$-labeled amino acids $(25 \mu \mathrm{Ci} / \mathrm{ml})$ under conditions as described for ${ }^{3} \mathrm{H}$ labeling of virus. About $2.5 \mathrm{~h}$ later, the medium was removed and the cells were lysed with $0.2 \mathrm{ml}$ of lysis buffer. The cell lysate was cleared by centrifugation for $2 \mathrm{~min}$ at $10,000 \times \mathrm{g}$, and the supernatant was stored at $-20^{\circ} \mathrm{C}$.

Preparation of antisera. Mouse anti-MHV-A59 serum was obtained from experimentally infected BALB/c mice as described previously (9a). Rabbit anti-MHV-A59 serum was prepared by immunization with gradient-purified, Triton X-100-disrupted virus. Four inoculations with $0.1 \mathrm{mg}$ of virus mixed with Freund complete adjuvant were given at 2-week intervals, followed by two injections with 1.0 and $0.4 \mathrm{mg}, 2$ and 4 weeks later, respectively. The resulting antiserum had a titer of $10^{5}$ in a plaque reduction assay $(50 \%$ reduction of $100 \mathrm{PFU}$ in conjunction with goat antirabbit immunoglobulin G [Miles Yeda Ltd., Rehovot, Israel] diluted 1:50). Both sera were able to precipitate all viral structural proteins.

Immunoprecipitation of proteins. Samples of oocyte homogenates $(50 \mu \mathrm{l})$ or from lysates of infected cells $(3 \mu \mathrm{l})$ were mixed with $7 \mu \mathrm{l}$ of anti-MHV-A59 serum. After overnight incubation at $4^{\circ} \mathrm{C}, 0.2$ volume of $3.0 \mathrm{M} \mathrm{KCl}$ was added, followed by $0.1 \mathrm{ml}$ of a $10 \%$ suspension of protein A-Sepharose (Pharmacia Fine Chemicals, Uppsala, Sweden) in TES containing $0.1 \%$ Triton X-100. Incubation was continued for $30 \mathrm{~min}$ before the immune complexes were collected by centrifugation for $2 \mathrm{~min}$ at $10,000 \times \mathrm{g}$, washed three times with $0.2 \mathrm{ml}$ of TES containing $0.1 \%$ Triton X-100, and finally dissolved in electrophoresis sample buffer (10 mM Tris-hydrochloride [pH 8.0], 1 mM EDTA, 10\% glycerol, $2 \%$ SDS, $5 \%$ 2-mercaptoethanol, $0.001 \%$ bromophenol blue).

Gel electrophoresis of proteins. SDS-polyacrylamide gel electrophoresis was performed in slab gels (10 cm long and $1.5 \mathrm{~mm}$ thick) containing $12.5 \%$ acrylamide, $0.1 \%$ bisacrylamide, $375 \mathrm{mM}$ Tris-hydrochloride (pH 8.8), and 0.1\% SDS. A 1-cm-long stacking gel containing $4 \%$ acrylamide, $0.1 \%$ bisacrylamide, 125 $\mathrm{mM}$ Tris-hydrochloride ( $\mathrm{pH} 6.8$ ), and $0.1 \%$ SDS was used. The reservoir buffer contained $50 \mathrm{mM}$ Tris base, $384 \mathrm{mM}$ glycine, and $0.1 \%$ SDS. Protein samples in electrophoresis sample buffer were heated for $3 \mathrm{~min}$ at $95^{\circ} \mathrm{C}$ before electrophoresis except for the virus samples which were run without prior heating to avoid aggregation of some of the proteins (12). Electrophoresis was at $100 \mathrm{~V}$ for about $5 \mathrm{~h}$. Radioactive polypeptides were detected by fluorography (6).

\section{RESULTS}

Isolation of virus-specific intracellular RNAs. To demonstrate the presence of subgenomic RNAs in Sac(-) cells infected with MHVA59 and to estimate their molecular weights, we previously used agarose gel electrophoresis after complete denaturation of the RNAs with glyoxal and dimethyl sulfoxide (9a). Since the reaction 
with glyoxal will affect the proper functioning of RNAs as messengers, preparative separation for translational purposes was performed by using a $1 \%$ agarose-6 $\mathrm{M}$ urea horizontal slab gel but omitting the glyoxal treatment. It is clear from Fig. 1A that the virus-specific RNAs of MHVA59-infected Sac(-) cells labeled with $\left[{ }^{3} \mathrm{H}\right]$ uridine in the presence of actinomycin $D$ were separated in this gel system without apparent breakdown, giving rise to a pattern similar to that obtained after glyoxal denaturation. Agarose gels containing $6 \mathrm{M}$ urea melt upon heating for 2 min at $65^{\circ} \mathrm{C}$. For this reason, RNA is easily recovered from such gels.

To purify MHV-A59-specific intracellular RNAs for injection into $X$. laevis oocytes, RNA was isolated from MHV-A59-infected $\operatorname{Sac}(-)$ cells by phenol extraction and ethanol precipitation. A poly(A)-containing fraction was prepared by oligodeoxythymidylic acid cellulose chromatography. A small sample of this fraction was analyzed by agarose gel electrophoresis after glyoxal-dimethyl sulfoxide denaturation. All virus-specific RNAs were present (data not shown). To the remainder of the poly $(A)^{+}$fraction, ${ }^{32} \mathrm{P}$-labeled RNA isolated from MHV-A59infected Sac $(-)$ cells grown in the presence of actinomycin $\mathrm{D}$ and ${ }^{32} \mathrm{P}_{\mathrm{i}}$ was added as a marker, and the sample was electrophoresed in an agarose-urea gel. Virus-specific RNAs were localized by autoradiography of the wet gel. Bands corresponding to RNAs $1,2,3,4$ and 5, 6, and 7 were excised, and the RNAs were recovered by phenol extraction and ethanol precipitation. To determine the validity of this procedure, we analyzed small samples of the RNA preparations by agarose gel electrophoresis after glyoxal-dimethyl sulfoxide denaturation. As shown in Fig. $1 B$, pure preparations of both RNA 3 and RNA 7 were obtained, whereas RNA 6 still contained some contamination of RNA 7. Similarly, RNAs 1 and 2 were obtained pure, but in the preparation of RNAs 4 and 5, which were excised from the urea gel and processed together, a significant amount of RNA 7 was also detectable (data not shown).

Translation of RNAs in X. laevis oocytes. The RNAs thus obtained were microinjected into $X$. laevis oocytes, which were subsequently incubated in the presence of $\left.{ }^{35} \mathrm{~S}\right]$ methionine. The oocytes were homogenized, and samples of the homogenates were analyzed directly by SDS-polyacrylamide gel electrophoresis. In only one case when oocytes were injected with RNA 7 was the synthesis of a novel, presumably viral, polypeptide observed (Fig. 2). Its molecular weight was estimated to be 54,000 . In no other cases were any such polypeptides detected above

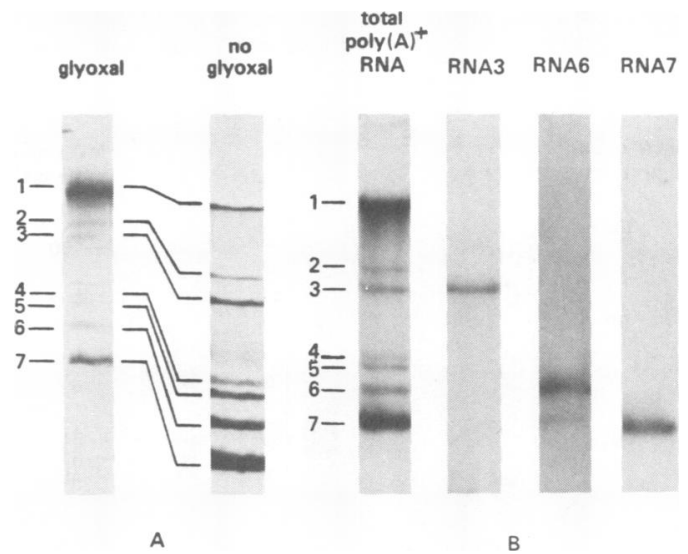

FIG. 1. (A) Effect of glyoxal-dimethyl sulfoxide denaturation on the electrophoretic separation of $M H V$. A59-specific intracellular RNAs in a $1 \%$ agarose-6 $M$ urea gel. Virus-specific RNAs were isolated by phenol extraction and ethanol precipitation from $M H V \cdot A 59$ infected Sac(-) cells labeled with $\left[{ }^{3} H\right]$ uridine in the presence of actinomycin $D$. One sample was denatured with glyoxal in 50\% dimethyl sulfoxide; another was heated and rapidly cooled in a sample buffer containing $0.25 \%$ SDS as described in the text. (B) Purification of MHV-A59-specific intracellular RNAs. Cultures of Sac(-) cells were infected with $M H V-A 59$ and incubated in the presence of actinomycin $D$ and $\left[{ }^{3} H\right]$ uridine. Cells were harvested at 9 $h$ p.i. RNA was isolated from the cell lysate by phenol extraction, and the poly $(A)^{+}$fraction was isolated by oligodeoxythymidylic acid cellulose chromatography. A sample of RNA extracted from $M H V \cdot A 59$-infected Sac $(-)$ cells grown also in the presence of actinomycin $\mathrm{D}$ but labeled with ${ }^{32} \mathrm{PO}_{4}$ was added as a marker, and the preparation was electrophoresed in a $1 \%$ agarose-6 M urea gel. RNA bands were visualized by autoradiography of the wet gel. Bands corresponding to RNAs 3, 6, and 7 were excised, melted, and phenol extracted. RNAs recovered after ethanol precipitation were analyzed in a $1 \%$ agarose slab gel after glyoxal-dimethyl sulfoxide denaturation. A sample of ${ }^{32} P$-labeled unfractionated poly $(A)^{+} R N A$ from infected cells was run as a marker in an adjacent lane of the gel.

the background of endogenous Xenopus proteins, as is shown for RNA 3 (Fig. 2).

Immunoprecipitation of translation products. For the identification of virus-specific translation products, immunoprecipitation was carried out on samples of cleared homogenates of the oocytes with an antiserum from mice that had survived MHV-A59-induced hepatitis. Only small amounts of the radioactivity incorporated by the oocyies appeared in immune complexes: $1.47 \%$ of the acid-insoluble $\left.{ }^{35} \mathrm{~S}\right]$ methionine was immunoprecipitable from oocytes injected with RNA 7, $1.05 \%$ was immunoprecipitable in re- 


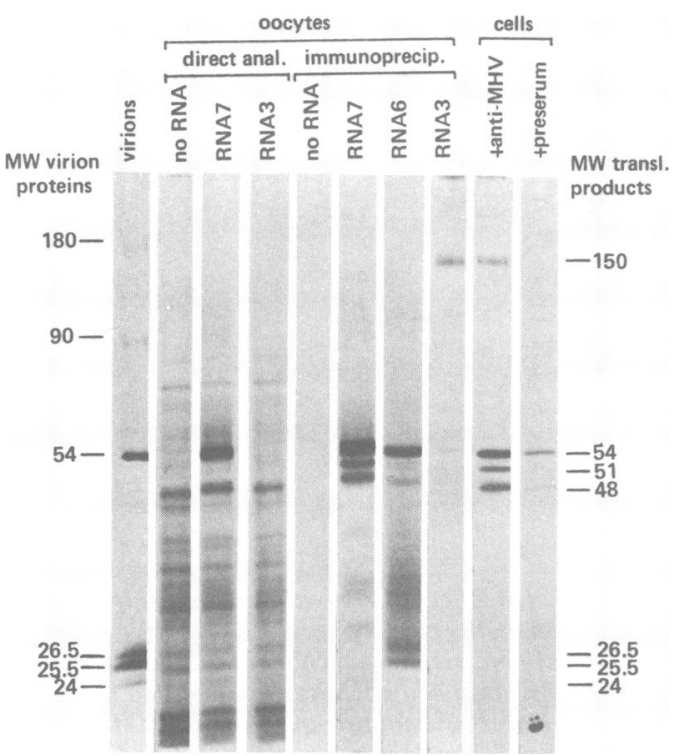

FIG. 2. Electrophoretic analysis of the translation products of MHV-A59-specific RNAs 3, 6, and 7. Oocytes were injected with RNA or with injection medium only, labeled with $\left.{ }^{35} S\right]$ methionine, and sub. sequently homogenized. Samples of the homogenates were taken for direct analysis in a $12.5 \%$ polyacrylamide gel. Other samples were used to prepare im. munoprecipitates. These were run in the same gel. Proteins of MHV-A59-infected Sac(-) cells precipitable with the same antiserum, using mouse preimmune serum as a control and ${ }^{3} \mathrm{H}$-labeled purified virion proteins were run for a comparison. Molecular weights $(M W)$ are indicated in thousands.

sponse to RNA 6, $0.25 \%$ was immunoprecipitable in response to RNAs 4 and 5, 0.05\% was immunoprecipitable in response to RNA 3, and $0.01 \%$ was immunoprecipitable in response to RNA 2. No virus-specific radioactivity was precipitated from the homogenate of oocytes injected with RNA 1. The immune complexes were analyzed by electrophoresis in SDS-polyacrylamide gels (Fig. 2). Injection of oocytes with RNA 7 resulted in the detection of three virus-specific polypeptides: one predominant polypeptide of about 54,000 daltons that had already been observed by direct analysis of the homogenate plus two smaller polypeptides of about 51,000 and 48,000 daltons. The same polypeptides were also produced when oocytes were injected with the preparation of RNA 6. As mentioned before, this preparation contained significant amounts of contaminating RNA 7. For this reason, the appearance of the RNA 7-specific polypeptides among the translation products was to be expected. However, three other polypeptides, having estimated molecular weights of 24,000 ,
25,500 , and 26,500, were detected; the latter two were dominant. Injection of $X$. laevis oocytes with RNA 3 gave rise to the synthesis of one virus-specific product with an estimated molecular weight of 150,000 . No translation products of RNAs 1, 2, and 4 and 5 were found, except in the immunoprecipitate of the translation products of RNA 4 and 5, the products of the contaminating RNA 7 appeared. When the immunoprecipitations were carried out with antiserum obtained from rabbits that had been immunized with disintegrated, purified MHV-A59-virions, the same results were obtained (data not shown). This implies that the virus-specific translation products described above are related to the structural proteins of MHV-A59.

Characterization of translation products. The electrophoretic mobilities in SDS-polyacrylamide gels of the polypeptides synthesized in oocytes in response to RNAs 3, 6, and 7 were compared with those of the MHV-A59 structural proteins and with the virus-specific proteins found in infected cells. It is clear from Fig. 2 that the 54,000-dalton polypeptide specified by RNA 7 coelectrophoresed with the presumed viral nucleocapsid protein. A protein of the same size is also prominent in MHV-A59-infected cells The other two RNA 7-specific polypeptides with molecular weights of 51,000 and 48,000 were only detected after immunoprecipitation. To establish whether these polypeptides are derived from the 54,000-dalton polypeptide, immunoprecipitation was carried out with purified virus labeled with ${ }^{32} \mathrm{P}_{\mathrm{i}}$, in which case only the nucleocapsid protein is labeled (11). As shown in Fig. 3, both smaller proteins appear to be phosphorylated and have thus arisen from the nucleocapsid protein.

The 24,000-, 25,500-, and 26,500-molecularweight polypeptides translated from RNA 6 comigrated with the lower-molecular-weight proteins found in purified MHV-A59 (Fig. 2). Their relative intensities also seemed to correspond.

No counterpart of the 150,000-dalton translation product of RNA 3 is present among the viral structural proteins. However, this polypeptide had the same electrophoretic mobility as one of the polypeptides that can be immunoprecipitated from homogenates of infected Sac(-) cells with an antiserum directed against the viral structural proteins.

\section{DISCUSSION}

Direct evidence is presented in this paper that at least three of the seven subgenomic RNAs induced in cells upon infection with coronavirus MHV-A59 are functional messengers. When in- 


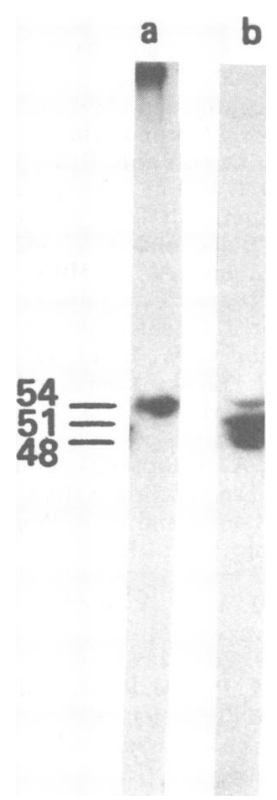

Fig. 3. Effect of immunoprecipitation on $M H V$. A59 nucleocapsid protein. MHV-A59 labeled in Sac(-) cells with ${ }^{32} P_{i}$ was purified from the culture fluid of the cells. Samples of the virus were analyzed by polyacrylamide gel electrophoresis either directly (a) or after immunoprecipitation with mouse antiMHV-A59 serum (b). Molecular weights are indicated in thousands.

jected into $X$. laevis oocytes, these RNAs direct the synthesis of discrete virus-specific polypeptides. This finding confirms our earlier conclusion, based on the polyadenylation of the subgenomic RNAs and their presence in polysomes, that multiple subgenomic messengers are involved in MHV-A59 multiplication (9a). Although a more detailed characterization of the translation products described is certainly required, some relevant inferences can be drawn.

RNA 7, the smaller subgenomic RNA, directs the synthesis of a polypeptide with a molecular weight of 54,000. Several arguments suggest that this protein, which is always found in infected cells in predominating quantities, represents the nucleocapsid protein. First, both proteins have similar electrophoretic mobilities in polyacrylamide gels. Second, immunoprecipitation of the 54,000-molecular-weight translation product induces the appearance of two new polypeptides, a phenomenon also observed with the corresponding protein present in infected cells (Fig. 2) and with the virion nucleocapsid protein (Fig. 3). A similar degradation during immunoprecipitation has been described by Siddell et al. (9) for the nucleocapsid protein of strain JHM. Apparently, the nucleocapsid protein is subject to proteolytic degradation even though protease inhibitors are present in the reaction mixture.

RNA 6 directed the synthesis of three lowermolecular-weight polypeptides. They were immunoprecipitated by anti-MHV-A59 serum and electrophoresed with the same mobility as the smaller virion proteins. In vitro iodination of purified virus with the lactoperoxidase-catalyzed reaction showed that all three are present in the viral envelope (P. J. M. Rottier and B. A. M. van der Zeijst, unpublished data). These proteins might be different forms of the same protein, differing in their degree of glycosylation. In addition to these polypeptides, significant amounts of 54,000-, 51,000-, 48,000-dalton products were immunoprecipitated from the homogenates of oocytes injected with RNA 6. Their synthesis could be accounted for by a very efficient translation of RNA 7 molecules contaminating the RNA 6 preparation. One cannot exclude, however, that RNA 6 itself is translated into these products.

A 150,000-molecular-weight polypeptide is produced upon translation of RNA 3. Although no protein of a similar size is found in purified virus, this polypeptide presumably is a structural precursor since it comigrated in a polyacrylamide gel with a protein induced by MHV-A59 infection of Sac(-) cells. This protein, which is a glycopeptide containing a protein moiety of about 110,000 daltons, can be immunoprecipitated with an antiserum raised in rabbits against the structural proteins of purified virus (unpublished data). The 110,000-dalton species probably corresponds to a 120,000 -dalton translation product synthesized in the reticulocyte cell-free system in response to total poly $(A)^{+}$RNA from MHV strain JHM-infected cells (9). Post-translational modification, i.e., glycosylation, does not occur in this system.

Siddel et al. (9) have also size fractionated the cytoplasmic poly(A) ${ }^{+}$RNA from MHV strain JHM-infected cells in sucrose-formamide gradients. Two RNAs sedimenting at $17 \mathrm{~S}$ and $19 \mathrm{~S}$ could be separated. In a cell-free system derived from L-cells, these RNAs directed the synthesis of the 60,000-dalton nucleocapsid protein and a 23,000-molecular-weight protein, respectively. Assuming that these RNAs are analogous to our RNAs 7 and 6, respectively, these observations are in good agreement with ours.

The sizes of the polypeptides synthesized in oocytes in response to MHV-A59 RNAs 3, 6, and 7 correspond to the theoretical values expected on the basis of our working model. According to this model, only the $1.6 \times 10^{6}$-dalton $5^{\prime}$-terminal region of RNA $3\left(3.0 \times 10^{6}\right.$ daltons) should be expressed, yielding a translation product with a molecular weight of at most about 160,000 . Sim- 
ilarly, a polypeptide with a molecular weight of up to about 30,000 is predicted to be obtained from the $0.3 \times 10^{6}$-dalton $5^{\prime}$-terminal part of RNA $6\left(0.9 \times 10^{6}\right.$ daltons). Finally, RNA 7 (0.6 $\times 10^{6}$ daltons) is supposed to act as a monocistronic messenger; when translated in ovo, a protein with a maximum size of about 60,000 daltons was to be expected.

No virus-specific translation products were observed upon injection of $X$. laevis oocytes with RNAs 1, 2, and 4 and 5. One reason for this might be that these RNAs do not encode viral structural proteins and that their products therefore were not immunoprecipitated. In addition, the amounts of the RNAs injected into the oocytes or their intrinsic efficiencies of translation may have been too low. To overcome these problems, we are currently scaling up the RNA preparation procedure, hoping that injection of saturating quantities of the messengers will allow the detection of products even without immunoprecipitation, as was already possible with RNA 7.

\section{ACKNOWLEDGMENTS}

We thank R. Huber for her hospitality, help, and advice and $M$. van Kleef-Koopmans for technical assistance with the oocyte injections. We are grateful to $M$. Maas Geesteranus and C. van Rooyen for the preparation of the manuscript.

\section{LITERATURE CITED}

1. Anderson, R., S. Cheley, and E. Haworth-Hatherell. 1979. Comparison of two strains of murine hepatitis virus. Virology 97:492-494.

2. Asselbergs, F. A. M., W. J. van Venrooy, and H. Bloemendal. 1978. Synthesis of lens crystallins in Xenopus oocytes as determined by quantitative immunoprecipitation. Eur. J. Biochem. 87:517-524.

3. Bond, C. W., J. L. Leibowitz, and J. A. Robb. 1979. Pathogenic murine coronaviruses. II. Characterization of virus-specific proteins of murine coronaviruses JHMV and A59V. Virology 94:371-384.

4. Gurdon, J. B. 1968. Changes in somatic cell nuclei inserted into growing and maturing amphibian oocytes. J. Embryol. Exp. Morphol. 20:401-414.

5. Gurdon, J. B., C. D. Lane, H. R. Woodland, and G. Marbaix. 1971. Use of frog eggs and oocytes for the study of messenger RNA and its translation in living cells. Nature (London) 233:177-182.

6. Laskey, R. A., and A. D. Mills. 1975. Quantitative detection of ${ }^{3} \mathrm{H}$ and ${ }^{14} \mathrm{C}$ in polyacrylamide gels by fluorography. Eur. J. Biochem. 56:335-341.

7. Robb, J. A., and C. W. Bond. 1979. Coronaviridae, p. 193-247. In H. Fraenkel-Conrat and R. R. Wagner (ed.), Comprehensive virology, vol. 14. Plenum Publishing Corp., New York.

8. Shatkin, A. J., A. K. Banerjee, and G. W. Both. 1977. Translation of animal virus mRNAs in vitro, p. 1-71. In H. Fraenkel-Conrat and R. R. Wagner (ed.), Comprehensive virology, vol. 10. Plenum Publishing Corp., New York.

9. Siddell, S. G., H. Wege, A. Barthel, and V.ter Meulen. 1980. Coronavirus JHM: cell-free synthesis of structural protein p60. J. Virol. 33:10-17.

9a.Spaan, W. J. M., P. J. M. Rottier, M. C. Horzinek, and B. A. M. van der Zeijst. 1981. Isolation and identification of virus-specific mRNA's in cells infected with mouse hepatitis virus (MHV-A59). Virology 108:424434.

10. Stern, D. F., and S. I. T. Kennedy. 1980. Coronavirus multiplication strategy. I. Identification and characterization of virus-specified RNA. J. Virol. 34:665-674.

11. Stohlman, S. A., and M. M. C. Lai. 1979. Phosphoproteins of murine hepatitis viruses. J. Virol. 32:672-675.

12. Sturman, L. S. 1977. Characterization of a coronavirus. I. Structural proteins: effects of preparative conditions on the migration of protein in polyacrylamide gels. Virology 77:637-649.

13. Sturman, L. S., and K. V. Holmes. 1977. Characterization of a coronavirus. II. Glycoproteins of the viral envelope: tryptic peptide analysis. Virology 77:650-660.

14. Tyrrell, D. A. J., D. J. Alexander, J. D. Almeida, C. H. Cunningham, B. C. Easterday, D. J. Garwes, J. C. Hierholzer, A. Kapikian, M. R. MacNaughton, and K. McIntosh. 1978. Coronaviridae: second report. Intervirology 10:321-328. 